\title{
ПРОБЛЕМЫ ПРИМЕНЕНИЯ МАШИННЫХ МЕТОДОВ ПРИ ВЫЯСНЕНИИ ПАТЕНТОСПОСОБНОСТИ ОБЪЕКТОВ
}

\author{
(Представил О. Киррет)
}

На современном этапе научно-технического прогресса автоматизация информации о научных исследованиях стала насущной необходимостью. Сюда же следует причислить информацию о патентоспособных объектах. Известно, что разработка новых прогрессивных химических и биологических технологических процессов, научное приборостроение в области химии, синтез новых веществ являются, как правило, результатом длительного труда целого коллектива ученых и специалистов и требуют больших материальных затрат. Отсюда вытекает основная цель патентования отечественных изобретений за·границей - защита экспорта или продажа лицензий.

При оформлении заявки на предполагаемое изобретение большой интерес для патентоведов и изобретателей представляет оценка патентоспособности данного предложения для его защиты авторским свидетельством СССР и патентами за рубежом. Критерии, на основании которых предложение признается изобретением, в разных странах различны $\left[{ }^{1-13}\right]$. Определение патентоспособности предполагаемого изобретения в СССР можно представить в виде формулы:

$$
\mathrm{H}_{0}^{(i)}=\mathrm{H} \cdot \mathrm{T} \cdot \mathrm{C} \cdot \Pi \text {, }
$$

где $И_{0}^{(i)}-$ изобретение $i$-го объекта,

$\mathrm{H}$ - новизна, причем Н есть функция от времени,

T - техническое решение задачи,

С - существенные отличия,

П - положительный эффект.

- Проверка сути предполагаемого изобретения с помощью формулы (1) в ходе оформления заявки на изобретение и в ходе ее государственной экспертизы во ВНИИГПЭ $\left[{ }^{14}\right]$ покажет, существует изобретение или нет. Так, если один из сомножителей формулы (1) окажется равным нулю, предмет заявки не может быть признан изобретением.

При этом встает ряд проблем. Первая проблема - есть ли возможность применить количественные критерии для оценки существенных отличий $\left[{ }^{15}\right]$.

Если признаки $A$ и $B$ известны, и $A$ создал эффект $A_{1}$, а $B-$ эффект $B_{1}$, и признаки $A$ и $B$ в совокупности создали только суммарный эффект $A_{1}+B_{1}$, то совокупность $A B$ не обладает существенными отличиями, и предмет заявки не признается изобретением:

$$
\left|\begin{array}{l}
A \\
A_{1}
\end{array}\right|+\left|\begin{array}{l}
B \\
B_{1}
\end{array}\right| \rightarrow\left|\begin{array}{c}
A+B \\
A_{1}+B_{1}
\end{array}\right| \text {. }
$$


Если же признаки $A$ и $B$ в совокупности создали, кроме суммарного эффекта $A_{1}+B_{1}$, дополнительный эффект $Z_{1}$, являющийся следствием совместного применения признаков $A$ и $B$, то совокупность $A B$ обладает существенными отличиями, и предмет заявки признается изобретением:

$$
\left|\begin{array}{l}
A \\
A_{1}
\end{array}\right|+\left|\begin{array}{l}
B \\
B_{1}
\end{array}\right| \rightarrow\left|\begin{array}{l}
A+B \\
A_{1}+B_{1}+Z_{1}
\end{array}\right| .
$$

Формула изобретения: объект $N$, о тлича ющй с я тем, что с целью $Z_{1}$ в нем (совокупно) применены признаки $A$ и $B$. В Институте химии АН ЭССР создано более 20 изобретений с формулой данного типа.

Если объект $N$, имеющий признаки $A, B, C$, создал эффект $A_{1}$, признак $D$ в другом объекте создал эффект $D_{1}$, и при добавлении признака $D$ в объект $N A B C$ создается суммарный эффект $A_{1}+D_{1}$, то совокупность $N A B C D$ не обладает существенными отличиями, и предмет заявки не признается изобретением:

$$
\left|\begin{array}{l}
N A B C \\
A_{1}
\end{array}\right|+\left|\begin{array}{l}
D \\
D_{1}
\end{array}\right| \rightarrow\left|\begin{array}{l}
N A B C D \\
A_{1}+D_{1}
\end{array}\right|
$$

Если при добавлении признака $D$ в объект $N A B C$, кроме суммарного эффекта $A_{1}+D_{1}$, создается дополнительный эффект $Z_{1}$, то совскупность $N A B C D$ обладает существенными отличиями, и предмет заявки признается изобретением:

$$
\left|\begin{array}{l}
N A B C \\
A_{1}
\end{array}\right|+\left|\begin{array}{l}
D \\
D_{1}
\end{array}\right| \rightarrow\left|\begin{array}{l}
N A B C D \\
A_{1}+D_{1}+Z_{1}
\end{array}\right| .
$$

Формула изобретения: объект $N$ с признаками $A B C$, отлича ющ и й я тем, что с целью $Z$ в нем применен признак $D$. В Институте химии АН ЭССР создано более 100 изобретений с формулой данного типа и, кроме того, есть несколько т. н. изобретений нового применения, когда объект $A$, примененный в качестве объекта $N$, создал эффект $Z$.

Предложение не обладает существенными отличиями и не признается изобретением, если

$$
\left|\begin{array}{l}
N A \\
Z
\end{array}\right| \rightarrow\left|\begin{array}{l}
M A \\
Z\left(Z_{1}\right)
\end{array}\right| .
$$

Если же изобретение нового применения уже известного объекта $A$ проявляет дополнительные свойства и создает новый эффект $Y$ или дополнительный эффект $\Delta Z$, то такое применение обладает существенными отличиями и признается изобретением:

$$
\left|\begin{array}{l}
N Z \\
A
\end{array}\right| \rightarrow\left|\begin{array}{l}
M A \\
Y(Z+\Delta Z)
\end{array}\right| .
$$

Формула изобретения: применение $A$ в качестве $M$ с целью $Y$.

Одним из критериев патентоспособности технического решения является мировая новизна, т. е. его неизвестность в СССР и за границей до даты приоритета заявки на изобретение. Блок-схема алгоритма определения патентоспособности изобретения приведена на рис. 1. На первом этапе определяют новизну технического решения [14]. Это наиболее. трудоемкий этап, где возникает вторая пробле м а - создание информационно-поисковой системы (ИПС) для патентоведа в целях выяснения патентоспособности объектов. 


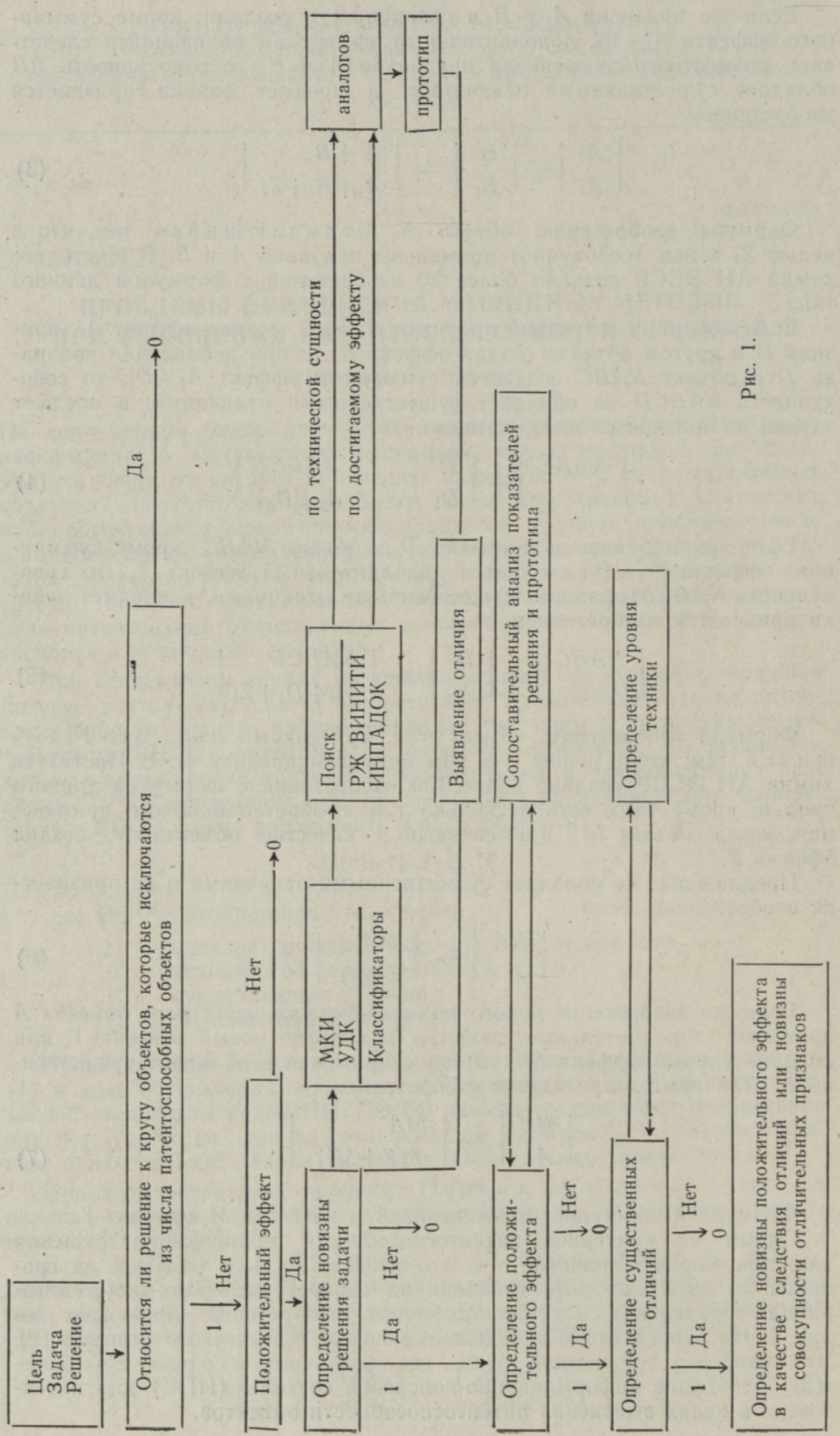




\section{OKOMYATEABHER OPBET NE}

25010 YOSHIUK? NiKAGOM!

CXRMA POAKGKCPOBHOPO AHOOEPEHUHAALWOPO YOUAKTRAR.

3009010

199611.2



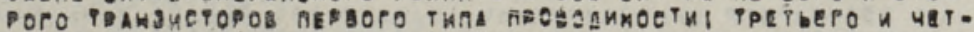

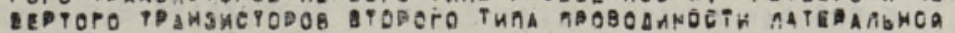
CTPYKTYOK, KHEQ TOPW.

$23023 \quad 0, M, B C H A O E$

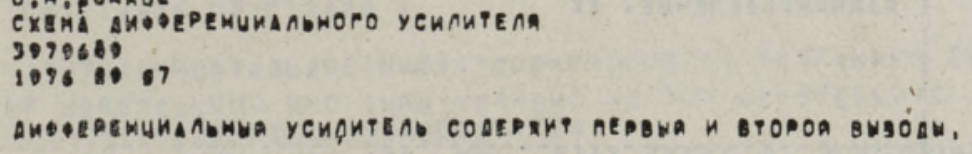

Рис. 2.

Из-за огромных массивов патентных фондов, длительного срока действия патентов (7-20 лет) и межклассификационных барьеров патентный поиск отнимает у высококвалифицированных специалистов месяцы рабочего времени. Сокращение времени на поиск - одна из главных проблем, решение которой возможно лишь путем создания автоматизированных ИПС.

Информационные системы можно подразделить на три категории. Первая - библиографическая с и стем а. Термин «библиографическое описание изобретения» широко применяется в двух основных значениях. Во-первых, под ним подразумевают вторичный документ, содержащий минимум расположенных в определенном порядке основных сведений, необходимых для идентификации первичного документа (оригинала патента) и раскрытия его содержания. Во-вторых, под ним понимают один из видов аналитико-синтетической обработки первичных документов. Әффективность библиографической системы тем выше, чем больше она высвобождает изобретателя и патентоведа от просмотра документов в целях установления их пертинентности при получении определенного количества релевантных документов. Библиографическое описание патентного документа отражает не только поисково-идентификационный, но и технико-информационный и правовой аспекты, и поэтому роль его в процессе определения патентоспособности весьма существенна. Эффективность библиографической системы определяюг:

1) технические средства (тип ЭВМ, вспомогательное и сервисное оборудование, средства оформления документов, устройства телеобработки),

2) информационное обеспечение (классификаторы Международной классификации изобретений (МКИ), Национальной классификации изобретений, УДК. и информационные источники),

3) лингвистическое обеспечение (совокупность научно-технических терминов),

4) программное обеспечение (обработка информации, математическое обеспечение задачи),

5) организационное обеспечение (инструкции операторов, технологи- 


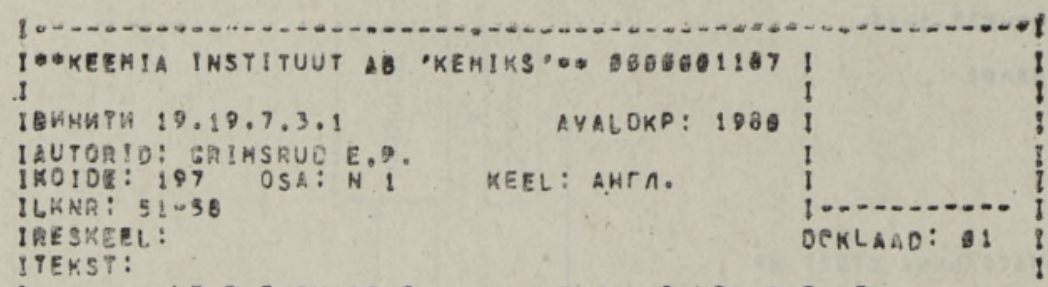

1 ALTERATION OF PHE ELECTROH-CAPTUEE DETECTOR

I D-CPONSE TO POLYCYCLIC AROUATIC HYOROCARBONS GY OXYGEN

IINE OF THE CARR!ER GAS - J. CHROHATEGR. RAPATP.SOI

PAPS GAKKAXPONATOPPAOUA ГASOBAA TAPAPP SSS TAPATP

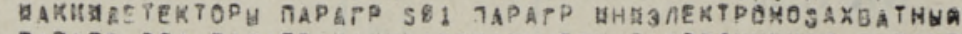

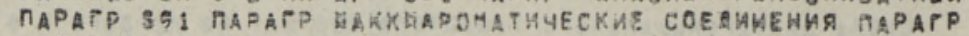

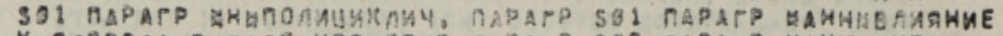

KИCAODOAA E PASE-KOCUTEME TAPAPP SB2 MAPAP DAHWICHECH

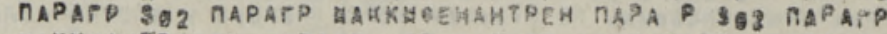

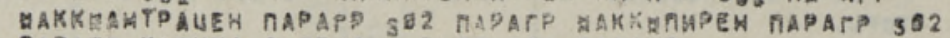

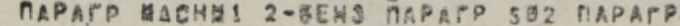

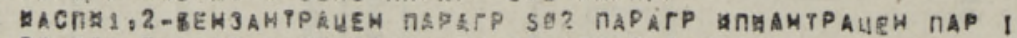

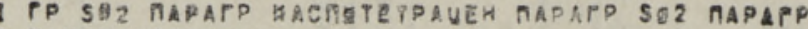

ПАНHLPA $3 A E A E H И E, ~ E X$

1

1

1



I SEMI-AUTOMATED FLUORIMETRIC HETHOD FOA YHE

I ESTIMATION OF URINIRY CATECHOLAMINES USING

I HIGH-PERPORHANCE LIGUIO EWROHATOGRAPHY $j$.

I CHROMAPOCR - BIOHED, APPL, TAPAPP SBI TAPAPP

I GKK

I SB 1 APAPP OKK GHOPAQPEHAAHH TAPAPP SGI TAPAPP

GAHHQORPEAEAEHUE B MOUE IX

1

1

1

i

Рис. 3.

ческие схемы, обработка данных в информационно-вычислительном центре),

6) обеспечение обмена информацией с другими системами (ИНПАДОК (Вена), ВИНИТИ и др.).

На рис. 2 изображен листинг библиографической системы «Патент».

Ее главная трудность состояла в том, что входная информация вводилась вручную.

Тремя секторами Института химии АН ЭССР - патентно-лицензионным, информационным и математического моделирования - создан инфобанк РЕТРОХИМ. Первичная информация вводится на магнитных лентах, выпускаемых центральными информационными и патентными органами: информация из ВИНИТИ - 24 файла в год (рис. 3) и патентная информация на базе ИНПАДОК - 52 файла в год (рис. 4).

ИПС для патентоведа, разработанная в Институте химии АН ЭССР, 


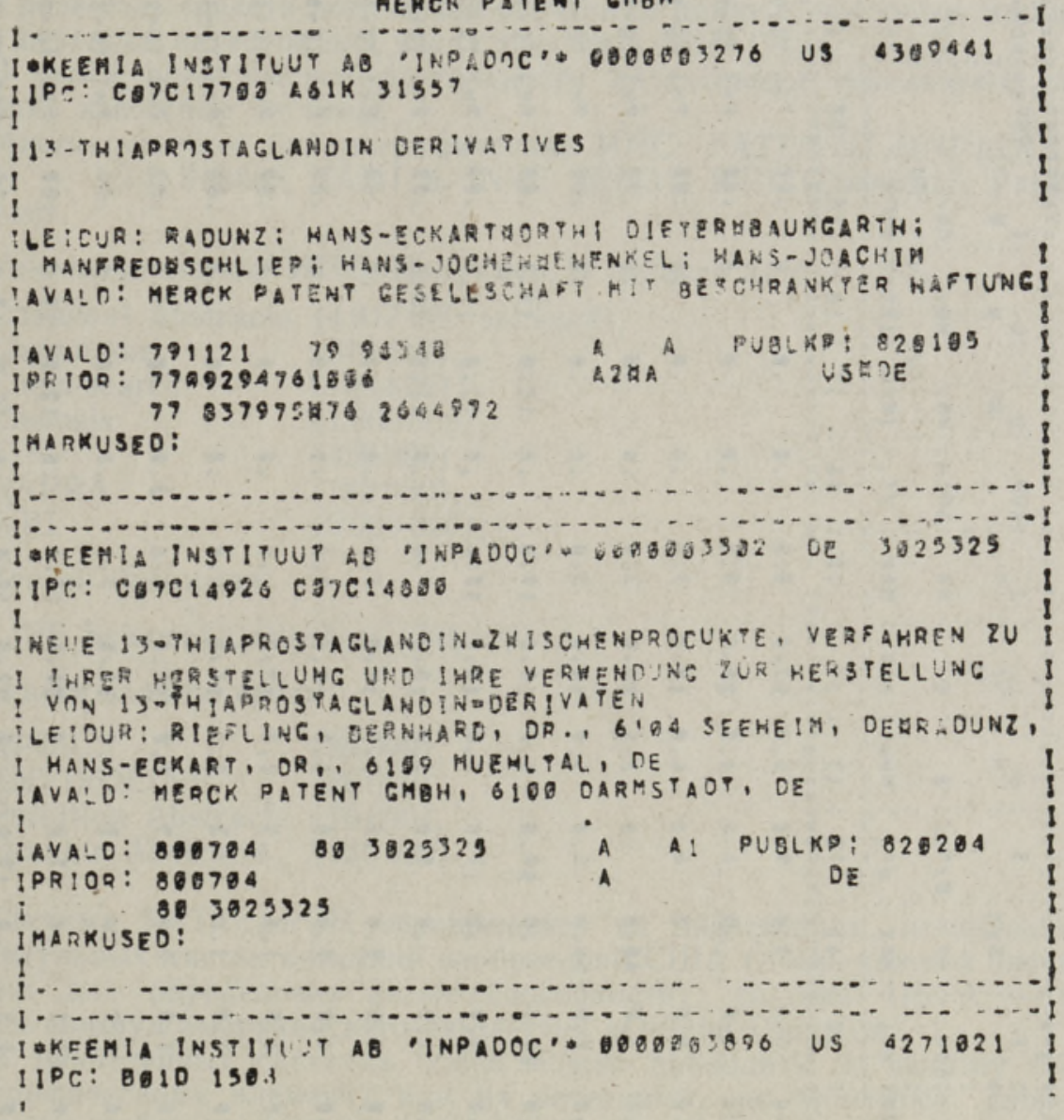

Рис. 4.

реализована на базе пакета прикладных программ АСОД под управлением ОС ЕС, которая позволяет проводить быстрый поиск как по элементам текста, так и по другим признакам (МКИ, автор, фирма, год издания и т. д.). Результаты поиска выводятся в виде листингов или воспроизводятся на экране дисплея. Инфобанк библиографических данных создан на базе ЭВМ ЕС 1022 и включает более 100000 источников, из которых в ходе патентных исследований активно используется приблизительно 25000.

Вторая система - фактографическая. Она содержит базы данных со стандартными вопросами [9] для определения новизны, положительного эффекта и уровня техники решения. На основе фактографических таблиц (рис. 5), составленных по данным каталогов и материалов фирм, можно регулярно проводить сравнение с результатамн опробования предполагаемого технического решения. Аналогично можно составить фактографические таблицы новых химических и биохимнческих веществ.

Третья система - докумен тальн а я. В этом случае поиск осуществляется по полным текстам патентов (с начала 80-х годов). В США приступили к созданию информационных и вычислительных систем по хранению, поиску и обработке данных с применением не только стандартных процедур поиска релевантной вопросу информации, 


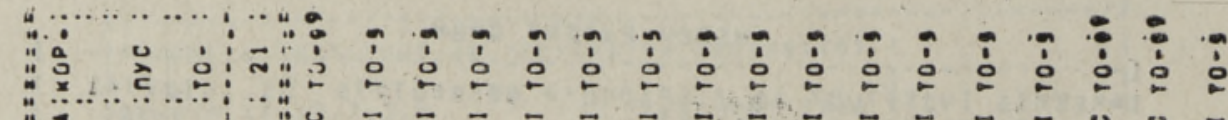

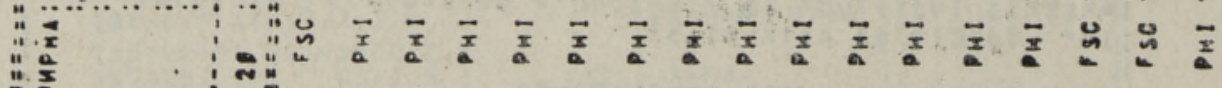

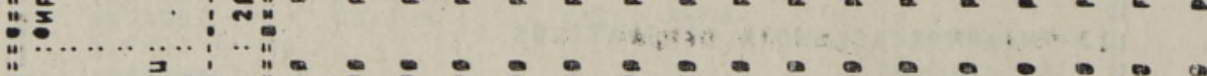

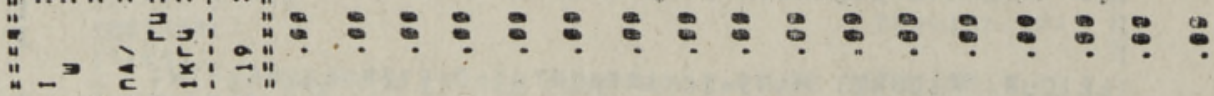
a d Ja

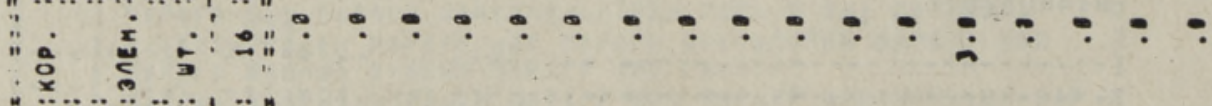


U - L (1).............

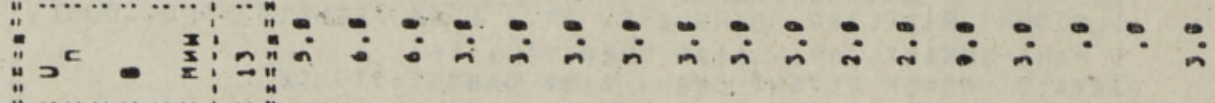
"u

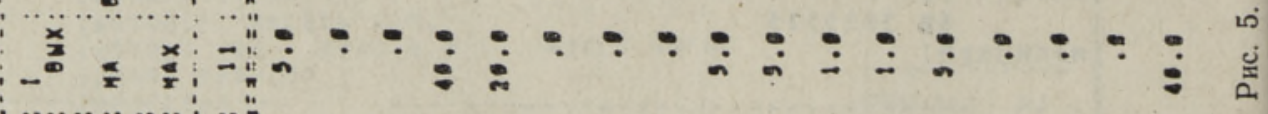

$$
\begin{aligned}
& \text { z. }
\end{aligned}
$$



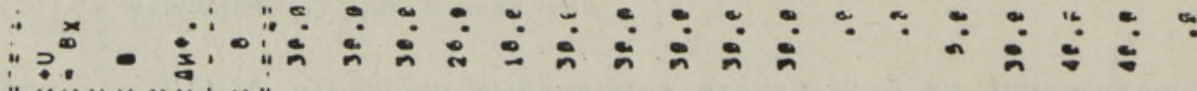

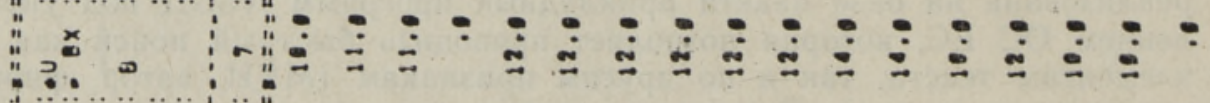

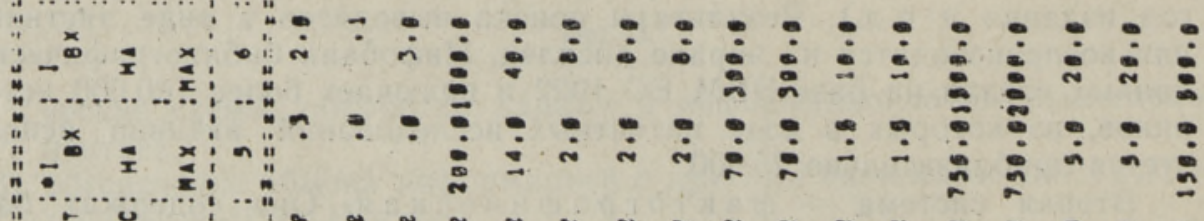

$$
\begin{aligned}
& \text { "I }
\end{aligned}
$$

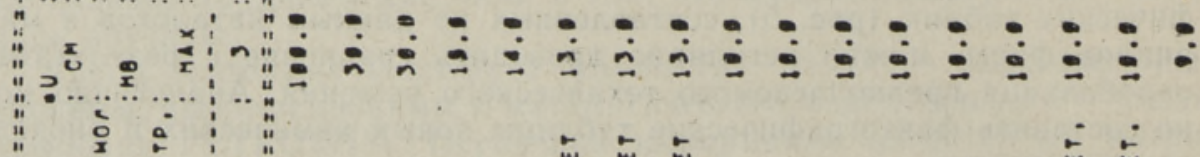

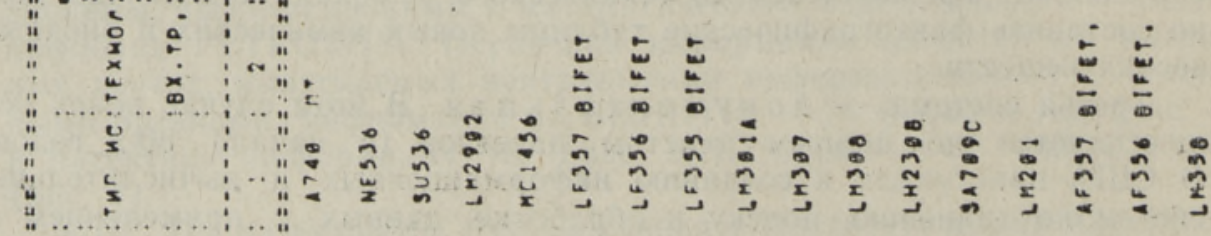


но и развитых средств логической обработки данных, программ машинного перевода патентов для ввода текстов в ЭВМ $\left[{ }^{10}\right]$.

В своей практической деятельности патентоведы используют следующие известные системы.

1. Многоаспектные библиографические ИПС: PATENTE (INPADOC), INP1 - 1,2,3 France, FAMI \& INVE (EPO), WPI (Derwent), Patolis (Japan)

2. Узкотематические ИПС. Например, в области химии:

Chemical Abstracts
Chemname
Chem-search
Chemsis
CIN
RAPRA
WPI

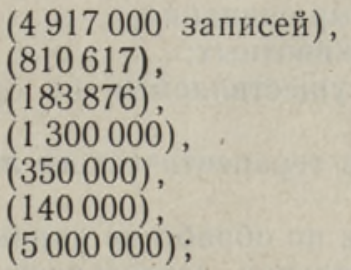

в области биохимии:

LIFE Sciences Collection (356 686);

в области защиты среды:
APTIC
ENVIROLINE
$(89000)$,
$(86000)$,
Pollution Abstracts (76000),
Oceanic Abstracts (120000).

Система PATSEARCH основывается на информации, помещаемой на титульных листах описаний изобретений США (очень важной информации для определения патентоспособности), система USPA - на тексте формул американского бюллетеня «Official Gazette».

В приведенных системах поиск можно проводить по любому библиографическому элементу или их сочетанию, по ключевым словам заглавия реферата в режиме пакетного поиска или диалога с запоминанием стратегии поиска. Для определения патентоспособности в системе USPA предусмотрено два экрана: на один выдаются тексты рефератов и формулы с видеодисков, на другой - чертежи.

Патентные законы капиталистических стран не содержат, как правило, общего легального определения изобретения. Они ограничиваются перечислением наиболее важных признаков, характеризующих предмет патентной охраны, вся сумма этих признаков охватывается понятием патентоспособности.

В начале 80-х годов в Западной Европе сложилась совершенно новая патентно-правовая ситуация - стала активно действовать Европейская патентная система (ЕПС), ставящая своей целью создать единую централизованную процедуру выдачи патентов для стран-участниц. Первые европейские патенты были выданы 15 января 1980 г.

Из капиталистических государств наиболее крупным партнером стран СЭВ по обмену технологиями является ФРГ, где для патентования изобретения в области химии существуют три возможности. Первая - это оформление чисто национальной заявки в Патентном ведомстве в Мюнхене (например, патент ФРГ № 2627077, который получил Институт химии АН ЭССР). Вторая - это европейский патент, который выдает Европейское патентное ведомство в Мюнхене. Третья это патент, который выдается по пути РСТ (Договор о патентной кооперации). О положительном эффекте ни в патентном законе ФРГ, ни в европейском ничего не говорится, но изобретательский уровень, особенно в области химии, практически доказывают через полезность. 
В производстве по выдаче европейского патента экспертиза патентоспособности осуществляется на основе законодательных норм, закрепленных в статьях $52-57$ ЕПС [7]. Поясним эти нормы, исходя из $\left[{ }^{2,7}\right]$

Предлагаемая блок-схема алгоритма (рис. 6) выполняет роль вспомогательного средства для достижения максимальной объективности при экспертизе патентоспособности.

Прямые исключения из сферы патентоспособных объектов:

1) открытия, научные теории, математические методы;

2) биологические способы выращивания;

3) сорта растений, породы животных;

4) способы диагностики, осуществляемые на организме человека или животных;

5) способы хирургического и терапевтического лечения организма человека или животного;

6) программы для установок по обработке данных;

7) планы, правила, мыслительная деятельность, игры и ведение торговли;

8) результаты художественного конструирования.

Самая сложная проблема при выяснении патентоспособности объектов - сопоставительный анализ показателей решения, прототипа и аналогов. Получен ряд авторских свидетельств (например №№ 801226, 744915), где сопоставительный анализ выполнен в виде листингов и отправлен во ВНИИГПЭ в качестве вспомогательного материала. В области химии при определении патентоспособности нового вещества мы всегда просматриваем материалы «Chemical Abstracts» и РЖ ВИНИТИ «Химия». Оба издания уже имеют вариант машинного поиска.

Для накопления реферативной информации по химии на магнитные ленты службы CAS («Chemical Abstracts Service») ежегодно записывается около 2,2 млн. документов (патенты, статьи, отчеты). Из общего потока отбираются документы с библиографическими данными. Из $10-20$ тыс. записей за неделю выбирается $25-35 \%$. Если патент признается основным, ЭВМ присваивает ему порядковый номер.

\section{Л ИТЕРА Т У Р А}

1. Pressman, D. R. Patent It Yourself! How to Protect, Patent and Market Your Inyentions. New York, 1979, 210.

2. Cornish, W. R. 'Die wesentlichen Kriterien der Patentfähigkeit europäischen Erfindungen. Neuheit und erfinderische Tätigkeit. - Gewerblicher Rechtsschutz und Urheberrecht, 1983, N 4, 221-226.

3. Application for chemical patents. - YUASA and HARA Journal (Japan), 1981, $8, \mathrm{~N} \mathrm{3}, 8-15$.

4. Yukishita, S., Guttman, D. S. Japanese patent specification and claims. - Patents and Licensing (Japan), 1983, XIII, 3, 7-12.

5. Abstracts of recent court decisions. - Patents and Licensing (Japan); 1979, IX, N $5,8-11$.

6. The Finnish Patent Law, Effective October 1, 1980. The Association of Finnish Patent Attorneys. Helsinki, 1981, 22.

7. Schwerdtel, E. Beurteilung von Erfindungen mit Hilfe eines Fragenschemas. Schweizerische Mitteilungen über gewerblichen Rechtsschutz und Urheberrecht, 1982 , N 11, 209-212.

8. Calvert, R. The Encyclopedia of Patent Practice and Invention Management. Huntington, 1974, 860 .

9. Bank, H., Fenat-Haessing, M., Roland, M. Patent Information and Documentation in Western Europe. München, Commission of the European Communities, 1981, 230.

10. Pollick, Ph. I. Processing of patent bibliographic data at chemical abstracts service. - World Patent Inform., 1981, 3, N 3, 128-131.

11. Патентный закон Франции. М., 1983, 107.

12. Тягульская Т. И., Моорлат О. Р. Критерии охраноспособности изобретений и их 




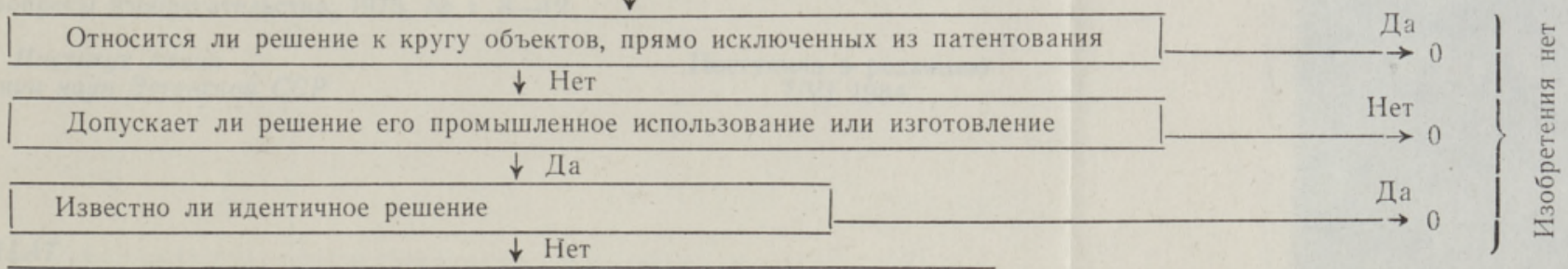

Известно ли техническое средство, ндентичное примененному

\section{Нет $\downarrow$}

Известно ли используемое свойство технического средства

Да



\begin{tabular}{|c|}
\hline $\begin{array}{c}\text { Можно ли добиться того же эффекта путем при- } \\
\text { менения другого технического средства }\end{array}$ \\
\hline Нет $\downarrow$ - \\
$\begin{array}{c}\text { Неожиданное } \\
\text { применение }\end{array}$ \\
$\begin{array}{c}\text { Применение тех- } \\
\text { нического экви- } \\
\text { валента }\end{array}$
\end{tabular}

$\downarrow$

Выводимо ли техническое средство из известных свойств того технического средства, которое известно



Выводимо ли техническое средство из известных свойств единственно известного технического средства с привлечением общедоступных знаний в соответствующей области техники

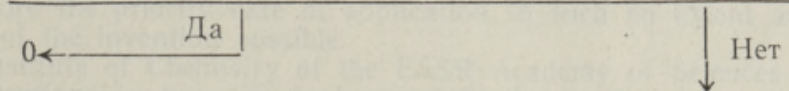

Выводимо ли техническое средство из двух или более несомненно взаимосвязанных известных средств



Неожиданная комбинация

\section{$\downarrow$ Да}

Известно ли используемое свойство технического средства

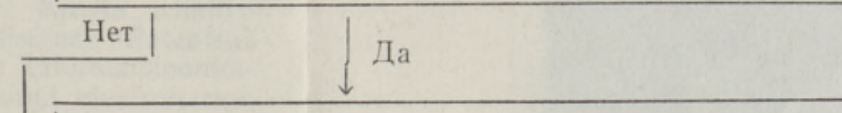

Продлено ли техническое предубеждение

\begin{tabular}{|c|c|}
\hline$\downarrow$ Нет & \\
\hline $\begin{array}{l}\text { Можно ли добиться того же эффекта путем при- } \\
\text { менения другого технического средства }\end{array}$ & $\mathrm{H}$ \\
\hline
\end{tabular}



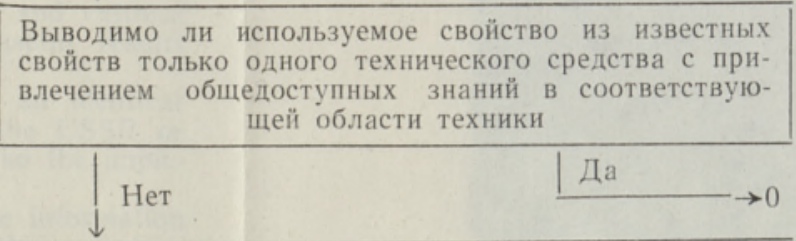

Выводимо ли используемое свойство из известных свойств двух или более несомненно взаимосвязанных технических средств

$\downarrow_{1}$ Нет

Неожиданный выбор

Рис. 6. Изобретение патентоспособно (1) и непатентоспособно (0). 
связь с уровнем, техники. - В кн.: Проблемные вопросы совершенствования системы выявления и защиты советских изобретений в процессе государственной научно-технической экспертизы. Тезисы докл. II Всес. конф. М., 1981, $34-36$.

13. Рогожина M. В. Критерий охраноспособности - изобретений в оценке уровня научно-технических разработок. - В кн.: Проблемные вопросы совершенствования системы выявления и защиты советских изобретений в процессе государственной научно-технической экспертизы. Тезисы докл. II Всес. конф. M., 1981, $12-14$.

14. Червова Л. В. Определение охраноспособности технического решения. Актуальные вопросы патентно-лищензионной работы. М., 1982, 155-172.

15. Киселев О. М. Охраноспособность изобретений в свете инструкции Э3-2-74. Вопросы изобретательства, 1975, № 1, 8-12.

Институт химии
Академии наук Эстонской ССР

Поступила в редакцию 7/VI 1984

\section{O. MOORLAT}

\section{MASINMEETODITE KASUTAMISE PROBLEEMID OBJEKTIDE PATENTSUSE VÄLJASELGITAMISEL}

Leiutistaotluste vormistamisel pakub patentoloogidele ja leiduritele suurt huvi patentsuse (objekti võime saada leiutisena kaitstud) hindamine, selleks et kaitsta tehnilisi lahendusi autoritunnistustega Nõukogude Liidus ja patentidega välismaal. Patentsus määratakse valemi abil. Seejuures on üks kõige töörohkemaid etappe informatsiooniotsing konkreetse objekti kohta. Selleks on patentoloogidele välja töötatud elektronarvutil töötavad infootsisüsteemid. Artiklis on toodud näiteid maailmas enamkasutatavatest otsisüsteemidest ja iseloomustatud ENSV TA Keemia Instituudis loodud masinotsisüsteemi «KEMIKS». Patentsuse määramiseks on toodud algoritmi plokkskeem autoritunnistuse ja Euroopa patendi jaoks.

O. MOORLAT

\section{PROBLEMS OF USING COMPUTER METHODS FOR ESTIMATING PATENTABILITY CRITERIA}

The problem of estimating patentability criteria is of great interest for inventors and patent specialists in the preparations for patent application. The invention is a new technical solution of a problem in any field of national economy, social and cultural sphere or state defence, which is of essential importance and gives useful results (formula (1)).

The solution should be regarded novel if the concept of this or of an identical solution has not been disclosed to an indefinite number of persons in the USSR or aisroad before the priority date of application to such an extent as to make the implementation of the invention possible.

The Institute of Chemistry of the ESSR Academy of Sciences uses the information on the inventions in two principal ways: firstly, in the preparations of the periodical general distribution of nonpatent items (VINITI) and, secondly, in the preparation of patent information in the INPADOC. 